\title{
Avaliação microbiológica de polpas de frutas congeladas
}

\author{
Microbiological evaluation of frozen fruit pulps
}

\section{Cristina Auler do Amaral SANTOS ${ }^{1}$, Ana Flavia Santos COELHO ${ }^{2}$, Solange Cristina CARREIRO ${ }^{1 *}$}

\begin{abstract}
Resumo
Foram analisadas 98 amostras de polpas de frutas congeladas de 8 sabores diferentes, comercializadas em uma feira livre da cidade de Palmas-TO. Foram determinados o $\mathrm{pH}$ das polpas, Número Mais Provável de coliformes totais e termotolerantes (NMP.g ${ }^{-1}$ ) e Unidades Formadoras de Colônia de bolores e leveduras (UFC. $\mathrm{g}^{-1}$ ). O pH médio das polpas variou entre 2,5 e 4,8. Apenas 5 amostras (4,3\%) apresentaram resultados positivos para coliformes totais e duas confirmaram a presença de coliformes termotolerantes e E. coli, com valores entre 0,3 e 0,9 NMP.g ${ }^{-1}$. Noventa por cento das amostras apresentaram contaminação por bolores e leveduras, sendo que as contagens variaram de $<10$ até $6,2 \times 10^{4} \mathrm{UFC} \cdot \mathrm{g}^{-1}$. Dentre as amostras que apresentaram bolores e leveduras, 29,6 \% não se enquadraram nos padrões estabelecidos pela legislação em vigor.
\end{abstract}

Palavras-chave: polpas de frutas; qualidade; coliformes; bolores; leveduras.

\begin{abstract}
Ninety-eight frozen pulps samples of eight different flavors commercialized in the city of Palmas, State of Tocantins, Brazil, were submitted to $\mathrm{pH}$ and microbiological analysis. The microbiological analysis included counts for total and termotolerant coliforms (MPN.g $\left.{ }^{-1}\right)$ and the determination of moulds and yeasts $\left(\mathrm{CFU} \cdot \mathrm{g}^{-1}\right)$. The $\mathrm{pH}$ was rate was 2.5 and 4.8 . Five samples $(4.3 \%)$ showed coliform contamination and two of them presented E. coli showing values between 0.3 and $0.9 \mathrm{MPN} . \mathrm{g}^{-1} .90 \%$ of the samples showed levels of moulds and yeast ranging from $<10$ to $6,2 \times 10^{4}$ CFU.g ${ }^{-1}$. Among them, $29.6 \%$ of the samples were considered unacceptable for consumption according to the legislation. Keywords: fruit pulps; coliforms; quality; moulds; yeasts.
\end{abstract}

\section{Introdução}

O Brasil é o maior produtor mundial de frutas in natura, porém, por serem perecíveis, grande parte dessas frutas sofre deterioração em poucos dias, tendo sua comercialização dificultada, especialmente a longas distâncias. A produção de polpas de frutas congeladas tem se destacado como uma importante alternativa para o aproveitamento dos frutos durante a safra, permitindo a estocagem das polpas fora da época de produção dos frutos in natura (BRUNINI; DURIGAN; OLIVEIRA, 2002).

Segundo a legislação brasileira do Ministério da Agricultura, polpa é o produto não fermentado, não concentrado ou diluído, obtido pelo esmagamento de frutos polposos (BRASIL, 2000). Além disso, devem ser preparadas com frutas sãs, limpas, isentas de matéria terrosa, de parasitas e detritos de animais ou vegetais. Não deverão conter fragmentos das partes não comestíveis da fruta, nem substâncias estranhas à sua composição normal, devendo ser observada também a presença ou ausência de sujidades, parasitas e larvas (SANTOS et al., 2004).

A maior parte da microbiota presente nas frutas reside em sua parte externa, sendo o seu interior praticamente estéril, a menos que haja uma ruptura em alguma parte da casca. As frutas e seus derivados são em geral alimentos ácidos e a elevada acidez restringe a microbiota deterioradora, especialmente os microrganismos patogênicos. A microbiota normalmente presente constitui-se em bolores, leveduras, bactérias lácticas e outros microrganismos ácido tolerantes como bactérias acéticas, Zymomonas e algumas espécies de Bacillus (SIQUEIRA; BORGES, 1997). A microbiota que contamina os produtos de frutas é normalmente proveniente das condições da matériaprima e da lavagem à qual estas são submetidas, além das condições higiênico-sanitárias dos manipuladores, equipamentos e ambiente industrial em geral.

A ANVISA, através da Instrução Normativa no 12 de 10/09/99, regulamentou os padrões de identidade e as características mínimas de qualidade para polpas de frutas destinadas ao consumo como bebida, estabelecendo valores máximos de $1{\mathrm{NMP} . g^{-1}}^{\mathrm{de}}$ coliformes e $5 \times 10^{3} \mathrm{UFC}^{-1} \mathrm{~g}^{-1}$ de bolores e leveduras. A resolução RDC no 12 , de 02/01/2001, que estabelece os padrões microbiológicos para alimentos, estabelece valor máximo de $10^{2} \mathrm{UFC} . \mathrm{g}^{-1}$ para coliformes termotolerantes, porém não estabelece padrões para bolores e leveduras.

Atualmente, o mercado de polpas tem apresentado expressivo crescimento, com grande potencial mercadológico, especialmente pela variedade de frutas e sabores agradáveis. Porém, a grande variedade de sabores não contemplados na legislação, aliado ao crescimento do mercado informal, podem

Recebido para publicação em 16/7/2007

Aceito para publicação em 4/3/2008 (002682)

${ }^{1}$ Laboratório de Microbiologia e Bioprocessos, Universidade Federal do Tocantins - UFT, Av. NS 15, ALCNO 14, s/n, bloco II, sala 4, CEP 77020-210, Palmas - TO, Brasil,

E-mail: solange@uft.edu.br

${ }^{2}$ Laboratório de Microbiologia de Alimentos, Universidade Federal do Tocantins - UFT

${ }^{*}$ A quem a correspondência deve ser enviada 
levar à comercialização de produtos sem uniformidade e sem controle sanitário adequado.

O objetivo do presente trabalho foi avaliar as características microbiológicas de diferentes polpas de frutas congeladas comercializadas em uma feira livre da cidade de Palmas - TO, através da análise de microrganismos do grupo coliformes, pesquisa de Escherichia coli e contagem de bolores e leveduras.

\section{Material e métodos}

\subsection{Obtenção das amostras}

Foram analisadas 98 amostras de 8 polpas de diferentes frutos, sendo 9 amostras de açaí, 11 amostras de acerola, 12 de bacuri, 12 de caju, 13 de cupuaçu, 12 de maracujá, 13 de murici e 16 de tamarindo. As polpas foram adquiridas de dois produtores em uma feira livre da cidade de Palmas - TO entre agosto de 2005 e junho de 2006, e mantidas em caixa térmica até seu processamento.

\subsection{Preparo das amostras}

\section{Determinação do pH das amostras}

Foram pesadas $10 \mathrm{~g}$ de cada amostra e diluídas em $90 \mathrm{~mL}$ de água destilada. Após a homogeneização, o pH das amostras foi determinado em potenciômetro modelo HI 255 Combine Meter, Hanna Instruments. Foram realizadas pelo menos 4 medidas de $\mathrm{pH}$ para cada amostra, sendo o valor final dado pela média aritmética simples das medidas. Os valores de $\mathrm{pH}$ foram avaliados estatisticamente quanto à análise de variância, e a comparação das médias, pelo teste de Tukey a 5\% de significância, com uso do software Sisvar (2000).

\section{Análises microbiológicas}

Após as amostras terem sido degeladas em temperatura ambiente, foram pesadas $25 \mathrm{~g}$ de cada amostra e transferidas assepticamente para frascos contendo $225 \mathrm{~mL}$ de água peptonada estéril (diluição $10^{-1}$ ). A partir dessa diluição, foram feitas as diluições seriadas até $10^{-3}$ com o mesmo diluente.

\subsection{Determinação do número mais provável $\left(\mathrm{NMP.g^{-1 } )}\right.$ de coliformes totais e termotolerantes}

Alíquotas de $1 \mathrm{~mL}$ de cada diluição foram inoculadas em séries de três tubos contendo $9 \mathrm{~mL}$ de caldo Lauril Sulfato Triptose (LST), com tubo de Duhran invertido (teste presuntivo). Os tubos foram incubados a $35{ }^{\circ} \mathrm{C}$ por $24-48$ horas. A partir dos tubos com leitura positiva (turvação e formação de gás), foram realizados os testes confirmativos para coliformes totais em caldo Lactose Bile Verde Brilhante (VB) a $35^{\circ} \mathrm{C}$ por 24-48 horas e coliformes termotolerantes em caldo Escherichia coli (EC) a $45,5^{\circ} \mathrm{C}$ por 24 horas.

Os valores de NMP.g ${ }^{-1}$ foram calculados de acordo com Silva et al. (2001).

\subsection{Determinação de Escherichia coli}

Para confirmação da presença de Escherichia coli, uma alçada de tubos contendo caldo EC que apresentavam turbidez, com ou sem produção de gás no interior do tubo de Durhan, foi semeada em placas de Petri contendo Ágar Eosina Azul de Metileno (EMB). As placas foram incubadas a $35^{\circ} \mathrm{C}$ por $24-48$ horas.

\subsection{Determinação de bolores e leveduras}

Para contagem de bolores e leveduras, foi utilizado o método de plaqueamento direto em superfície das diluições $10^{-1} \mathrm{e}$ $10^{-2}$, em meio Ágar Batata Dextrose acrescido de 0,2 mg. $\mathrm{mL}^{-1}$ de cloranfenicol. Alíquotas de $100 \mu \mathrm{L}$ foram semeadas na superfície do Ágar BD e as placas foram incubadas a $22^{\circ} \mathrm{C}$ por 3 a 5 dias. Os resultados foram expressos pelo número de Unidades Formadoras de Colônia por grama de material (UFC.g ${ }^{-1}$ ).

\section{Resultados e discussão}

A Tabela 1 mostra os valores médios de $\mathrm{pH}$ obtidos para cada polpa e as contagens de coliformes totais e termotolerantes, pesquisa de E. coli, e contagens para bolores e leveduras. Os valores médios de $\mathrm{pH}$ das polpas ficaram entre 2,5, para as polpas de tamarindo, e 4,8, para as polpas de açaí, mostrando-se ligeiramente superiores aos encontrados por Lima et al. (2001), que obtiveram valores de 1,8 e 4,0, respectivamente.

Os resultados obtidos nas contagens de coliformes totais demonstraram que apenas 5 amostras $(4,3 \%)$ apresentaram

Tabela 1. Resultados das análises microbiológicas para bolores e leveduras, coliformes totais e termotolerantes e $\mathrm{pH}$.

\begin{tabular}{|c|c|c|c|c|c|c|c|c|}
\hline \multirow[t]{2}{*}{ Polpas } & \multirow[t]{2}{*}{$\mathrm{pH}$} & \multicolumn{2}{|c|}{$\begin{array}{l}\text { Bolores e leveduras } \\
\left.\text { (UFC. } \mathrm{g}^{-1}\right)\end{array}$} & \multicolumn{2}{|c|}{$\begin{array}{l}\text { Coliformes totais } \\
\left(\mathrm{NMP}^{-1}\right)\end{array}$} & \multicolumn{2}{|c|}{$\begin{array}{c}\text { Coliformes termotolerantes } \\
\left(\mathrm{NMP.g}^{-1}\right)\end{array}$} & \multirow[t]{2}{*}{$\begin{array}{l}\text { Pesquisa de E. col } \\
\text { ausência/presença }\end{array}$} \\
\hline & & Mínimo & Máximo & Mínimo & Máximo & Mínimo & Máximo & \\
\hline Açaí (9) & $4,8^{\mathrm{D}}$ & $1,7 \times 10^{3}$ & $8,7 \times 10^{3}$ & $<10$ & $4,0 \times 10^{1}$ & $<10$ & $4,0 \times 10^{1}$ & $+(1)$ \\
\hline Acerola (11) & $3,2^{\mathrm{B}, \mathrm{C}}$ & $<10^{*}$ & $2,3 \times 10^{4}$ & - & - & - & - & - \\
\hline Bacuri (12) & $3,0^{\mathrm{A}, \mathrm{B}}$ & $<10^{*}$ & $8,0 \times 10^{3}$ & - & - & - & - & - \\
\hline Caju (12) & $3,2^{\mathrm{B}, \mathrm{C}}$ & $5,0 \times 10^{2 *}$ & $6,2 \times 10^{4 *}$ & $<10$ & $9,0 \times 10^{1}$ & - & - & - \\
\hline Cupuaçu (13) & $3,2^{\mathrm{B}, \mathrm{C}}$ & $<10^{\star}$ & $3,9 \times 10^{3}$ & - & - & - & - & - \\
\hline Maracujá (12) & $2,8^{\mathrm{A}, \mathrm{B}}$ & $<10^{*}$ & $2,5 \times 10^{4}$ & $3,0 \times 10^{1}$ & $4,0 \times 10^{1}$ & $<10$ & $4,0 \times 10^{1}$ & $+(1)$ \\
\hline Murici (13) & $3,7^{\mathrm{C}}$ & $<10^{*}$ & $1,7 \times 10^{4}$ & - & - & - & - & - \\
\hline Tamarindo (16) & $2,5^{\mathrm{A}}$ & $<10^{*}$ & $3,2 \times 10^{4}$ & - & - & - & - & - \\
\hline Padrão federal & - & \multicolumn{2}{|c|}{${ }^{a} 5 \times 10^{3}$} & & & \multicolumn{2}{|c|}{${ }^{\mathrm{b}} 10^{2}$} & - \\
\hline
\end{tabular}

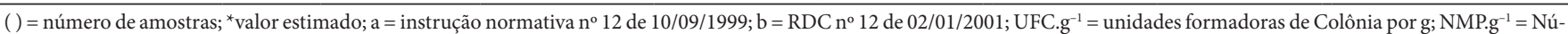
mero mais provável por g. Valores de $\mathrm{pH}$ com a mesma letra na coluna não são significativamente diferentes, a nível de $5 \%$, pelo teste de Tukey. 
resultados positivos para coliformes totais, sendo 3 de maracujá, 1 de caju e 1 de açaí. Dentre elas, 2 (1 de açaí e 1 de maracujá) confirmaram a presença de coliformes termotolerantes e E. coli, com valores entre $3 \times 10^{1}$ e $9 \times 10^{1} \mathrm{NMP.g}^{-1}$, estando dentro dos padrões estabelecidos pelo regulamento técnico $R D C n^{\circ} 12$, de $02 / 01 / 2001$ que preconiza valor máximo de $10^{2} \mathrm{NMP.g}^{-1}$ (BRASIL, 2001). O baixo valor de $\mathrm{pH}$ apresentado pela maioria das polpas pode representar um fator limitante para o crescimento de bactérias patogênicas, mantendo os índices de contaminação bacteriana em níveis baixos. Contaminação por coliformes totais e termotolerantes em polpa de maracujá também foi encontrada por Leite et al. (2000) e Lima et al. (2001), estando, provavelmente, associada à manipulação inadequada durante o processamento da matéria-prima, ou à contaminação de equipamentos.

Oitenta e oito amostras $(89,8 \%)$ apresentaram contaminação por bolores e leveduras, sendo que as contagens variaram de $<10$ até $6,2 \times 10^{4} \mathrm{UFC} . \mathrm{g}^{-1}$. Tal fato pode ser parcialmente atribuído ao elevado teor de carboidratos normalmente presentes nas polpas de frutas, além do caráter ácido das polpas. Embora o baixo $\mathrm{pH}$ favoreça o desenvolvimento desses microrganismos, não houve uma relação direta entre o pH e uma maior ou menor contagem de bolores e leveduras nas diferentes polpas. Dentre as polpas que apresentaram contaminação por bolores e leveduras, $29(29,6 \%)$ não se enquadraram nos padrões estabelecidos pela Instrução Normativa 12 de 10/09/99, a qual preconiza um máximo de $5 \times 10^{3}$ UFC.g ${ }^{-1}$.

Nascimento et al. (1999), ao estabelecerem o perfil microbiológico de polpas produzidas e comercializadas na cidade de São Luís - MA, constataram que $100 \%$ das amostras apresentaram contaminação por bolores e leveduras, apresentando contagens entre $1,0 \times 10^{5} \mathrm{e} 1,1 \times 10^{8} \mathrm{UFC}^{-g^{-1}}$. Hoffmann et al. (1997), Feitosa et al. (1999), Leite et al. (2000) e Lima et al. (2001), analisando a qualidade microbiológica de polpas comercializadas nos Estados de São Paulo, Paraíba, Pernambuco, Bahia e Ceará, observaram a presença de bolores e leveduras, encontrando valores entre $<10$ e $7,8 \times 10^{5} \mathrm{UFC}^{-1} \mathrm{~g}^{-1}$, dados que concordam com aqueles obtidos no presente trabalho.

Segundo Franco e Landgraf (2003), baixas contagens de bolores e leveduras são consideradas normais (não significativas) em alimentos frescos e congelados. No entanto, contagens elevadas representam, além do aspecto deteriorante, que pode levar inclusive à rejeição do produto, um risco à saúde pública devido à possível produção de micotoxinas por algumas espécies de bolores.

Apesar de 70,4\% das amostras apresentarem-se dentro dos padrões microbiológicos para bolores e leveduras e apenas 2 amostras apresentarem-se em desacordo com relação a coliformes termotolerantes, as elevadas contagens de bolores e leveduras, associadas com a presença de bactérias do grupo coliformes, reforçam a hipótese de processamento inadequado e/ou recontaminação pós-processamento, o que pode ser explicado pela qualidade insatisfatória da matéria-prima, manipulação inadequada e equipamento sujo ou com sanitização insatisfatória.

\section{Conclusões}

Os dados obtidos no presente trabalho mostraram que as polpas analisadas se encontram dentro dos padrões estabelecidos pela legislação vigente com relação a coliformes totais e termotolerantes, porém $29,6 \%$ das amostras apresentaram valores acima do permitido para bolores e leveduras. Esses resultados sugerem uma falta de controle sanitário, evidenciando que as condições higiênicas durante o processamento, operações de limpeza, escolha de matérias-primas e condições de armazenamento não devem estar de acordo com as boas práticas de fabricação (BPF).

\section{Agradecimentos}

Os autores agradecem ao Conselho Nacional de Desenvolvimento Científico e Tecnológico $(\mathrm{CNPq})$ a concessão da bolsa de iniciação científica à primeira autora.

\section{Referências bibliográficas}

BRASIL. MINISTÉRIO DA AGRICULTURA DO ABASTECIMENTO. Instrução Normativa n 12/99, de 13/09/99. Padrões de Identidade e Qualidade para Polpas de Frutas. Diário Oficial da República Federativa do Brasil, Brasília, DF, 13 set. 1999, Seção I, p 72.

BRASIL. MINISTÉRIO DA AGRICULTURA DO ABASTECIMENTO. Instrução Normativa $n^{\circ}$ 01/00, de 07/01/00. Regulamento técnico geral para fixação dos padrões de identidade e qualidade para polpa de fruta. Diário Oficial da República Federativa do Brasil, Brasília, DF, 10 jan. 2000, Seção I, p.54-58.

BRASIL. AGÊNCIA NACIONAL DE VIGILÂNCIA SANITÁRIA. Resolução RDC n 12, de 02/01/2001. Regulamento Técnico sobre padrões microbiológicos para alimentos. Diário Oficial da República Federativa do Brasil, Brasília, DF, 10 jan. 2001, Seção I, p. 45-53.

BRUNINI, M. A.; DURIGAN, J. F.; De OLIVEIRA, A. L. Avaliação das alterações em polpa de manga "Tommy-Atkins" congeladas. Revista Brasileira de Fruticultura, v. 24, n. 3, p. 651-653, 2002.

FEITOSA, T.; BASTOS, M. S. R.; OLIVEIRA, M. E. E. B.; MUNIZ, C. R.; BRINGEL, H. F.; ABREU, S. C. Qualidade microbiológica de polpas de frutas produzidas comercialmente nos Estados da Paraíba e Pernambuco. Higiene Alimentar, v. 12, n. 66/67, p. 111-115, nov/dez, 1999.

FRANCO, B. D. G.; LANDGRAF, M. Microbiologia de alimentos. 2 ed. São Paulo: Editora Atheneu, 2003.

HOFFMANN, F. L. et al. Microrganismos contaminantes de polpas de frutas. Ciência e Tecnologia de Alimentos, v. 17, n. 1, 1997

LEITE, C. C. et al. Avaliação Microbiológica de polpas congeladas de frutas produzidas no Estado da Bahia. Higiene Alimentar, v. 11, n. 78-79, p. 69-73, 2000.

LIMA, J. R.; MARTINS, S. C. S.; SILVA, J. L. A. Avaliação de popas de frutas congeladas comercializadas no estado do Ceará através de indicadores microbiológicos. Higiene Alimentar, v.15, n.88, p. 62-66, 2001.

NASCIMENTO, A. R. et al. Perfil microbiológico de polpas de acerola (Malpighia glabal) e abacaxi (Ananas comosus), produzidas e comercializadas na ilha de São Luís, MA. Higiene Alimentar, v. 13, n. 62 , p. 44-47, 1999.

SANTOS, F. A. et al. Análise qualitativa de polpas congeladas de frutas produzidas pelo SUFRUTS, MA. Higiene Alimentar, v. 15, n. 119, p. 14-22, 2004.

SILVA, N.; JUNQUEIRA, V. C. A.; SILVEIRA, N. F. A. Manual de métodos de análise microbiológica de alimentos. 2 ed. São Paulo: Livraria Varela, 2001.

SIQUEIRA, R. S.; BORGES, M. F. Microbiologia de frutas e produtos derivados. In: TORREZAN, R. (Coord.). Curso de processamento de frutas. Rio de Janeiro: EMBRAPA/CTAA, 1997. p. 2-13.

SISVAR, Sistema para análise de variância, para Windows. Versão 4.3. Lavras: Universidade Federal de Lavras, 2000. 